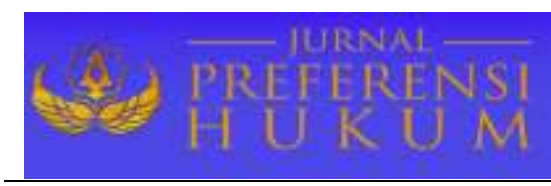

Jurnal Preferensi Hukum | ISSN: 2746-5039

Vol. 2, No. 2 - Juli 2021, Hal. 233-237| Available online at https://www.ejournal.warmadewa.ac.id/index.php/juprehum

DOI: https://doi.org/10.22225/jph.2.2.3314.233-237

\title{
PENYALAHGUNAAN PERBINCANGAN INTERAKTIF DALAM APLIKASI BIGO LIVE SEBAGAI MEDIA KOMUNIKASI YANG BERMUATAN TINDAK PIDANA PORNOGRAFI
}

\author{
Kadek Indra Prayogi, Anak Agung Sagung Laksmi Dewi, I Made Minggu Widyantara \\ Fakultas Hukum Universitas Warmadewa, Denpasar-Bali, Indonesia \\ indraprayogi82@gmail.com, laksmidewi29@gmail.com, mademinggu21@gmai.com
}

\begin{abstract}
Abstrak
Perkembangan dibidang teknologi informasi telah memberikan sumbangsi yang sangat besar bagi berkembangnya akses dunia. Pola dan aspek kehidupan masyarakat juga lebih mudah mengikuti perkembangan zaman melalui teknologi. Selain itu juga muncul dampak negatif yaitu munculnya kejahatan yang ikut mengalami perkembangan, salah satunya yaitu kejahatan tindak pidana pornografi dalam aplikasi Bigo Live. Penelitian ini bertujuan untuk mengkaji pengaturan hukum perbincangan interaktif dalam aplikasi Bigo Live dan menganalisis sanksi tindak pidana penyalahgunaan aplikasi Bigo Live yang bermuatan pornografi. Penelitian didesain dengan penelitian hukum normatif, dengan pendekatan Perundang-undangan. Data yang digunakan adalah data hukum primer dan sekunder. Hasil penelitian menunjukkan bahwa pengaturan tentang perbincangan interaktif aplikasi Bigo Live yang mengandung kejahatan pornografi secara umum dimuat pada KUHPidana bab XIV mengenai tindak kejahatan terhadap perbuatan asusila pada pasal 282 ayat (1), serta untuk memperkuat dasar hukumnya kejahatan pornografi dimuat juga pada UU ITE daam pasal 27 ayat (1) pasal 45 ayat (1), serta UU Pornografi pada pasal 4 ayat (1), 29, 31, dan 32. KUHPidana, UU Pornografi, dan UU ITE yang memiliki tujuan mempermudah penuntasan suatu kejadian mengenai tindak pidana pornografi dalam aplikasi Bigo Live. Sanksi pidana terhadap penyalahgunaan aplikasi Bigo Live diatur pada pasal 282(1) KUHP, UU ITE pada ayat (1) pasal 27, dan UU pornografi pada Pasal 4 ayat (1)
\end{abstract}

Kata Kunci: Aplikasi Bigo Live,Tindak Pidana, Pornografi

\begin{abstract}
Developments in Information Technology have contributed greatly to the evolution of the world. The era also influences the lifestyle of people, including crime, for example, the pornography crime in Bigo Live. The problems are I) How is the legal arrangement for interactive conversations in the Bigo live application in relation to the enactment of the pornography law? and 2) What is the punishment for misuse of the Bigolive application as a media communication that contains pornography? The purpose of this research is to find out the legal arrangements for the crime of pornography in the Bigo live application in Indonesia as well as to find out criminal sanctions against criminal acts of misusing the Bigo live. The method used is the normative method. The statutory regulations that are used as references in solving criminal cases of abuse of the Bigo live application are article 282 paragraph (I) of the Criminal Code, the !TE Law in article 27 paragraph (I) jo 45 paragraph (I), and 4 paragraph (I), 29, 31, and 32 in Pornography Law.
\end{abstract}

Keywords: Abuse, Bigo Live Application, Pornography Crime

\section{PENDAHULUAN}

Perkembangan yang begitu cepat dalam dunia informasi dan teknologi membawa kemajuan terhadap aspek pada segala bidang kehidupan masyarakat. Tidak dapat dihindari perkembangan yang begitu pesat. Hal ini menimbulkan dampak positif bagi individu serta menimbulkan berbagai konflik hukum yakni tindak kejahatan (Rahardjo, 2002). Jenis perbuatan pidana dalam memakai sarana elektronik yaitu berisikan bagian-bagian pornografi contohnya dalam aplikasi yang bernama aplikasi Bigo live . Aplikasi Bigo live adalah aplikasi yang dipergunakan dalam menyebarluaskan secara nyata individu secara maya melewati kamera telepon genggam dan dapat juga dilihat oleh anggota-anggota lainnya dalam bigo live. Bigo live juga menjajakan laba berupa uang tunai hasil dari penyiaran secara langsung dengan pola ditukarkannya berlian yang sudah ditimbun, paling sedikit ditarik yakni 6.700 berlian atau sejajar dengan dua juta rupiah. Hal ini yang menyebabkan beberapa pihak rela melakukan aksi yang vulgar agar mendapatkan diamond dari penontonya dan berpotensi melanggar norma kesusilaan serta dapat dikatakan melakukan kejahatan pornografi. 
Kejahatan Mayantara adalah wujud atau ruang baru dari kejahatan saat ini yang menarik minat manusia di belahan Negara di dunia (Wahid \& Labib, 2005). Kejahatan di dunia maya yakni salah satu dampak buruk dari perkembangan yang begitu cepat di bidang IT yang memiliki akibat negatif yang menyeluruh bagi kehidupan masyarakat era globalisasi contohnya adalah pornografi (Barda Nawawi, 2007 I). Perbuatan hukum pornografi adalah perbuatan dengan semua modus dan polanya menyangkut dengan foto, pola awal dari suatu gambar, reka adegan, coretan tangan, suara, animasi, kartun, obrolan, gerak badan, serta pesan Iainya melalui bermacam pola alat percakapan atau penampilan dihadapan semua orang, yang berisi eksploitasi seksual yang bertentangan dengan aturan pelecehan seksual pada kehidupan masyarakat yang dicantumkan dalam UU dan dipidana untuk siapa saja yang melaksanakan tindakan tersebut. Objek pornografi memuat dua unsur yakni memuat eksploitasi seksual dan bertentangan dengan aruran. Sedangkan KUHP menyatakan pelanggaran kesusilaan (Chazawi, 2016). Kejahatan pornografi diatur dalam KUHPidana pada pasal 282 (1) dan UU Nomor 11 Tahun 2008 tentang ITE Pasal 27 ayat (1) dan mengerucut ke pengaturan pada UU No 44 Tahun 2008 tentang Pomografi Pasal 4 ayat (I), 29, 31 dan 32 dengan sanksi yang sangat jelas tercantum pada ketentuan pasalnya.

Nadia, (2018) Konten yang ditampilkan melalui aplikasi streaming bigo live yang melanggar kesusilaan yaitu memosting gambar dan video yang flugar disebut sebagai tindak pidana pornografi, maka pelaku penyalahgunaan bigo live telah memenuhi unsur kesalahan sehingga pelaku dapat dibebankan pertanggungjawaban pidana padanya. Tindakan penyiaran konten melalui platform media sosial sehingga pedoman perilaku penyiaran beserta penerapan sanksinya tetap tunduk kepada ketentuan yang diatur dalam UU ITE beserta peraturan-peraturan turunannya (Febrian, 2020). Dalam hukum Indonesia perilaku pornografi dikategorikan sebagai gambar, sketsa, ilistrasi, foto, tulisan, suara, bunyi, gambar bergerak atau animasi, gerak tubuh dan pesan lain yang mempertunjukkan di muka umum yang mengandung nuansa kecabulan dan eksploitasi seksual yang melanggar norma dalam masyarakat, apa bila dengan sengaja atau tidak melakukan hal di atas maka dipidana sesuai UU No. 44Tahun 2008 tentang Pornografi dan UU Nomor 11 Tahun 2008 tentang informasi dan transaksi elektronik (Ummah, 2017). dari uraian latar belakang di atas serta teori penelitian terdahulu, maka penelitian ini dilakukan dengan tujuan mengkaji pengaturan hukum perbincangan interaktif dalam aplikasi Bigo Live dan menganalisis sanksi tindak pidana penyalahgunaan aplikasi Bigo Live yang bermuatan pornografi

\section{METODE PENELITIAN}

Penelitian ini dikaji menggunakan hukum normatif yang menjadikan norma hukum sebagai objek dan pendekatan masalah dengan mengkaji sumber kepustakaan dan konseptual normna yang sudah ada. Bahan hukum primer yaitu berpedoman terhadap peraturan Perundang-undangan dan keputusan yang inkra, sedangkan bahan hukum tersier diperoleh dari jal hukum, buku hukum, serta internet yang memuat penyebaran konten pornografi dalam perspektif hukum positif di Indonesia (Bambang, 2002). Data diperoleh dengan cara mencatat, mengutip, membaca, maupun meringkas literatur yang mengacu terhadap penyalahgunaan aplikasi Bigo Live yang bermuatan Pornografi. Setelah data semuanya terkumpul tahap terakhir menganalisis untuk memilih yang sesuai dengan topik dari masalah yang sedang diteliti dengan sistematis dan mengaitkannya dengan bahan hukum lainnya .

\section{HASIL DAN PEMBAHASAN}

\section{Pengaturan Perbincangan Interaktif Aplikasi Bigo Live Sebagai Tindak Pidana Pornografi dalam Peraturan Perundang-undangan di Indonesia}

Perbuatan pornografi adalah perbuatan dengan semua modus dan polanya menyangkut dengan foto, pola awal dari suatu gambar, reka adegan, coretan tangan, suara, animasi, kartun, obrolan, gerak badan, serta pesan Iainya melalui bermacam pola alat percakapan atau penampilan dihadapan semua orang, yang berisi eksploitasi seksual yang bertentangan dengan aturan pelecehan seksual pada kehidupan masyarakat yang dicantumkan dalam UU dan dipidana untuk siapa saja yang melaksanakan tindakan tersebut. Objek pornografi memuat dua unsur yakni memuat eksploitasi seksual dan bertentangan dengan aruran. Sedangkan KUHP menyatakan pelanggaran kesusilaan

Pornografi dapat diartikan foto-foto seksual yang bisa didapat pada bentuk foto dan video menurut UU No 44 tahun 2008 tentang pornografi. Secara cabang ilmu pomografi bersumber dari 2 kosa kata ialah pornos dan graft. Porno dimaksud tindakan asusila dalam hal yang berkaitan dengan 
seksual, atau tindakan yang berkarakter tidak beretika atau cabul, selanjutnya graft ialah gambar atau coretan tangan, yang dalam makna menyeluruh masuk ke dalam mannequin, yang berisi memperlihatkan atau mengilustrasikan sesuatu yang bersifat menyerang rasa kehormatan masyarakat. Prnyataan Muntaqo dan Burhan Bungin Pomografi di media massa terbagi dalam beberapa bentuk

a. Pornografi, gambar-gambar seksual yang dapat didapat pada wujud foto dan video

b. Porno teks, ialah ciptaan asusila terkait karangan berbagai jenis hubungan seksual dalam wujud cerita, pengalaman individu secara teliti yang dalam artian vulgar, jadi orang akan merasa menonton sendiri, menjalani atau melaksanakan sendiri kejadian seks

c. Porno suara, suara dan kalimat-kalimat yang dilontarkan individu secara nyata atau tidak nyata, bahkan secara terselubung atau terbuka mengenai kegiatan seksual

d. Pornoaksi, yakni suatu visualisasi, kegiatan gerakan, gerakan tubuh yang secara kealpaan atau sengaja guna menarik timbulnya keinginan seksual.

Kejahatan terhadap kesusilaan menjadi dua yaitu kejahatan kesusilaan dan kejahatan kesopanan yang diluar bidang kesusilaan, seperti kejahatan pornografi dan kejahatan melanggar kesusilaan umum. (Muhammad, 2019). Kejahatan ini diatur ansiknya dalam Buku II Bab XIV yaitu Pasal 281- 299 KUHP dan kejahatan pelanggaran terhadap kesusilaan diatur dalam Pasal 30 I, 504, 505 KUHP dan juga pada Buku Ill Bab VI dari Pasal 532 - 547 KUHP hal ini menunjukan bahwa tindakan kejahatan kesusilaan merupakan suaru benruk pelanggaran norma-norma hukum, agama, dan sosial. Namun dalam proses berkembangnya pengaturan serta penegakan hukum terkait penyebaran konten pornografi sebagai cyber crime pada KUHP lebih luas atau Undang-undang terkait seperti UU Pornografi dan UU ITE lebih kompleks dibandingkan dengan KUHP. Selain dalam KUHP, perbuatan hukum pornografi masuk aturan di Undang-undang ITE pada pasal 27 ayat (I). Pasal 27 ayat (1 ) Undang-undang ITE Pasal 45 ayat (1) UU ITE, Perbuatan hukum pornografi khususnya diatur dalam UU Pornografi di kasus ini menggunakan pasal Pasal 4 ayat (1), 29 sampai pada Pasal 32.

Dalam Undang-Undang ini menegaskan secara lugas bagian pemidanaan dari suatu tindak pidana menyebarkan, serta menggunakan konten pornografi dengan menyesuaikan pada tingkatan suatu perbuatan pidana yang dilaksanakan. Di samping itu penitik beratkan juga diberikan terhadap pelaku tindak pidana yang dilakukan oleh korporasi dengan menambahkan hukuman utama serta pemberian hukuman tambahan. Sedangkan untuk memberikan perlindungan terhadap korban pornografi, undang - undang ini mewajibkan kepada semua pihak, dalam hal ini negara, Lembaga-lembaga atau instansiinstansi terkait, keluarga, dan semua orang untuk memberikan pembinaan, pendampingan, pemulihan sosial, kesehatan fisik dan mental bagi setiap anak yang menjadi korban atau pelaku pornografi.

\section{Sanksi Tindak Pidana Penyalahgunaan Bigo Live Sebagai Media Komunikasi yang Bermuatan Pornografi}

Bigo Live sudah diunduh oleh 10 juta orang di Android. Hal ini mengindikasikan bahwa aplikasi Bigo Live luar biasa meningkat popularitasnya, mengingat baru beberapa bulan saja diluncurkan. Namun sangat disesali, hal tersebut berdampak pada penyalahgunaan oleh sebagian penggunanya untuk memamerkan aurat dan hal-hal erotis serupa, yang dapat dianggap telah melanggar nilai-nilai kesusilaan yang dipegang oleh masyarakat di Negara ini. Sebenarnya pihak Bigo Live sendiri (khususnya di Indonesia) sudah menentukan aturan-aturan tertentu yang bertujuan untuk menjadi batasan bagi para penggunanya dalam siaran agar tetap sesuai dengan norma hukum yang ada. Aturan-aruran tersebut antara lain para pengguna dilarang untuk menampilkan konten yang masuk dalam unsur pomografi, mengutarakan kebencian, pelecehan, dan merokok, melaksanakan perbuatan kekerasan dan Intimidasi, menyebarkan, dan tipu muslihat.

Dengan diberlakukannya aturan-aturan tersebut, pihak Bigo Live akan melakukan banned kepada siapapun penggunanya apabila menyalahi salah satu atau keseluruhan dari aturan aturan tersebut diatas. Tahapan banned yang dilakukan dimulai dari banned dalam jangka waktu tertentu, sampai banned permanen terhadap akun pengguna yang melanggar. Sesungguhnya terdapat kesepakatan antara pihak Bigo Live dengan para penggunanya yang menjamin data-data pribadi penggunanya seperti yang terlampir dalam Bigo Terms Of Service And Privacy Policy. Oleh sebab itu jika ada pelanggaran dari pengguna aplikasi ini maka dapat dilakukan penyelidikan sesuai dengan kesepakatan, maka data-data pengguna yang bersangkutan dapat diserahkan oleh pihak Bigo Live untuk kemudian diproses oleh penyidik. 
Dalam ilmu hukum pidana mengenal dua bentuk kesalahan antara lain, bagian yang disengaja dan yang tidak disengaja yang hanya berlaku sebagai perbuatan pidana dan bukan sebagai pelanggaran. terkait definisi keinginan, atas keinginan tersebut ditujukan untuk Tindak pidana, dampak perbuatan pidana, dan Suatu kejadian yang masuk perbuatan pidana.

Perbuatan pidana cuma menunjukkan terhadap apa yang dilarang dan di intimidasinya suatu kejahatan dengan pidana, dikarenakan pada pertanggungjawaban pidana ialah tidak dihukum, apabila tidak terdapat pelanggaran. Menurut Moeljatno, (2002), manusia tidak dapat diancam pidana, apa bila seseorang tersebut tidak melaksanakan kejahatan, tidak selalu dia dapat dipidana. Maka dari itu penyalahgunaan aplikasi Bigo Live ini dapat dijerat dengan pasal 282 KUHP tentang transaksi pornografi . Menurut Oemar Seno Adji menerangkan arti dari tindak pidana kesusilaan yang tidak dibatasi mengenai pornografi, namun termasuk juga perihal mengenai pelecehan dan permainan melanggar hukum (judi). Dengan demikian, kejahatan asusila dalam arti umum tidak hanya mencakup permasalah pornografi melainkan memuat tentang zinah serta pelanggaran seksual lainya (Widodo, 2006). Sesuai UU Pornografi ini sanksi-sanksi yang dijatuhkan bagi pelaku sesuai dengan pasal 4 ayat( 1) terdapat didalam Pasal 29 karena pelaku dengan sengaja melakukan penjual belian video atau foto yang bermuatan pornografi dan pelaku juga sama saja dengan sengaja melakukan penyebaran video atau foto pornografi melaJui media internet. Dengan ini pelaku akan dikenai hukuman jeruji besi tercepat 6 bu Ian dan terlama 12 bu Ian atau dikenai pidana dibayar dengan uang termurah Rp 250.000.000,00 dan terbanyak Rp 6.000.000.000,00 dan bisa juga pelaku akan dikenai kedua duanya tergantung bagaimana hasil sidang pengadilan yang akan dijatuhkan oleh pelaku. Dal am Pasal 31 dan 32 pelaku dapat dikenakan hukuman jeruji besi terlama 4 tahun atau pidana dibayar dengan uang terbanyak dua milyar rupiah.

\section{SIMPULAN DAN SARAN}

\section{Simpulan}

Dari hasil analisis data penelitian, dapat disimppulkan bahwa Pengaturan tentang perbincangan interaktif laplikasi Bigo Live yang mengandung kejahatan pornografi secara umum dimuat pada KUHPidana bab XIV mengenai tindak kejahatan terhadap perbuatan asusila pada pasal 282 ayat (I), serta untuk memperkuat dasar hukumnya kejahatan pornografi dimuat juga pada UU ITE daam pasal 27 ayat (1) pasal 45 ayat (1), serta UU Pornografi pada pasal 4 ayat (1), 29, 31,dan 32. KUHPidana, UU Pornografi, dan UU ITE yang memiliki tujuan mempermudah penuntasan suatu kejadian mengenai tindak pidana pornografi dalam aplikasi Bigo Live. Sanksi pidana terhadap penyalahgunaan aplikasi Bigo Live diatur pada pasal 282(1) KUHP dapat dipenjara selam 1 tahun 6 bulan atau uang denda termahal empat ratus limapuluh ribu rupiah, pada UU ITE pada ayat (1) pasal 27 dapat dihukum menggunakan penjara terlama enam tahun denda satu miliar rupiah. UU pornografi pada Pasal 4 ayat (1) dipenjara tersingkat enam bulan juga paling lam dua belas tahun dan pembayaran denda termurah dua ratus lima puluh juta rupiah dan terbanyak enam milyar rupiah.

\section{Saran}

Terkait simpulan penelitian di atas, adapun saran yang diberikan yaitu kepada lembaga terkait pemerintah untuk mengadakan pengawasan secara tegas terkait penggunaan aplikasi di internet yang disalahgunakan seperti Bigo Live dapat langsung diblokir oleh para penegak hukum yang tentunya bekerja sama dengan masyarakat. Bagi masyarakat pelaku agar tidak mengulangi perbuatan yang dilakukanya dan menggunakan internet, media sosial, dan aplikasi-aplikasi seperti bigo live dengan semestinya serta selalu berhati-hati dalam melakukan tindakan agar tidak melanggar hukum. Selannjutnaya peneliti menyadari bahwa penelitian ini terbatas pada kajian nalisis sansik hukum saja, maka disarankan kepada peneliti berikutnya untuk melakukan penelitian terkait hal ini dari perspektif yang berbeda.

\section{DAFTAR PUSTAKA}

Bambang, W. (2002). Penelitian Hukum dalam Praktek. Jakarta: Sinar Grafika. Chazawi, A. (2016). Tindak Pidana Pornografi. Jakarta Timur. Sinar Grafika.

Febrian, E. (2020). Tinjauan Yuridis Mengenai Pengawasan terhadap Pedoman Perilaku Penyiaran Platform Media Sosial di Indonesia. Jurnal Lex Renaissance, 5(3), 573-591.

Moeljatno. (2002). Asas-Asas Hukum Pidana. Jakarta. Rineka Cipta. 
Muhammad, R. i. (2019). Pembaharuan Hukum Pidana Indonesia. Yogyakarta. U II Press.

Nadia, C. S. (2018). Pertanggungjawaban Pidana terhadap Pelaku Penyalahgunaan Aplikasi Streaming "Bigo Live" dalam Konten Pornografi. Jurnal Ilmiah Mahasiswa Bidang Hukum, 2(4), 697-708.

Rahardjo, A. (2002). Cyber Crime Pemahaman dan Upaya Penanggulangan Kejahatan Berteknologi. Bandung. Citra Aditya Bhakti.

Ummah, S. R. (2017). Pornografi Ditinjau dari Hukum Positif dan Hukum Pidana Islam. Jurnal Pemikiran Dan Pembaharuan Hukum Islam, 2(2), 26-35.

Wahid, A., \& Labib, M. (2005). Kejahatan Mayantara (Cyber Crime),. Bandung. PT.Rafika Aditama. Widodo, I. G. (2006). Aspek Yuridis Pornografil/Aksi Memahami Wewenang Diskresi dalam Penyidikan Tindak Pidana Pornografi/Aksi. Surabaya. Airlangga University Press. 